\title{
QUADRINHOS, LITERATURA E A \\ INTERTEXTUALIDADE
}

COMICS, LITERATURE AND INTERTEXTUALITY

CÓMICS, LITERATURA Y LA INTERTEXTUALIDAD

MARIA CRISTINA XAVIER DE OLIVEIRA ${ }^{1}$

\footnotetext{
${ }^{1}$ Doutora na área de Estudos Comparados de Literatura pela Universidade de São Paulo (USP), com a tese: $A$ arte dos Quadrinhos e o Literário - a contribuição do diálogo entre o verbal e o visual para a reprodução e inovação dos modelos clássicos da cultura. Ministra cursos, palestras e workshops. É dramaturga e trabalha como editora na elaboração e coordenação de projetos editoriais, além de participar do grupo de pesquisas Produções Culturais e Literárias para Crianças e Jovens da Universidade de São Paulo (USP).
} 
RESUMO: A relação entre quadrinhos e literatura tem se mostrado uma forma eficiente para a criação das mais diversas narrativas. Pouco explorado no que diz respeito ao aproveitamento pela literatura do material produzido nos quadrinhos, o movimento inverso, ou seja, o uso de material literário para a elaboração de obras em quadrinhos tem desenvolvido inúmeros enredos. Tal diálogo permite uma veiculação de ideias de formas diferentes, revelando outras maneiras de "ler" e compreender o mundo que nos cerca.

ABSTRACT: The relation between comics and literature have been shown to an efficient form of the creation of the most different narratives. Just a little explored regarding the literature exploitation of the produced material in comics, the reverse movement, in other words, the literary material use for the elaboration of comic books has developed countless plots. Such dialogue allows a display of ideas in different ways, revealing other ways of "reading" and understanding the world around us.

RESUMEN: La relación entre cómics y literatura se mostra una forma eficiente para la creación de las más diversas narrativas. Se explota poco el aprovechamiento hecho por la Literatura sobre el material que se produce en los cómics, sin embargo, el movimiento inverso, el uso del material literario para la elaboración de los cómics, desarrolla innumerables enredos. Tal diálogo permite una difusión de ideas y de formas diferentes, revelando otras maneras de "leer" y comprender el mundo que nos rodea.

PALA VRAS-CHAVE: Quadrinhos; Literatura; Intertextualidade.

IKEYWORDS: Comics; Literature; Intertextuality.

PALABRAS CLAVE: Cómics; Literatura; Intertextualidad.

$\cos$

\section{INTRODUÇÃ̃o}

Ao observarmos a inter-relaçáo entre a literatura e as histórias em quadrinhos (HQs), um dos modos mais utilizados de se estabelecer a interação entre os dois meios artísticos é a adaptação de clássicos literários. Contudo, não é apenas por essa via que o diálogo entre ambas as artes pode ocorrer. Além das tradicionais adaptaçôes cuja gradação vai desde narrativas mais próximas ao original até aquelas que apresentam novas formas de 
reconstrução da obra-base, também temos os diálogos intertextuais, incluindo-se, nesse último, citações, alusôes, paródias, sátiras além de outras formas de intersecções.

A intertextualidade, termo proposto pela filósofa e crítica literária Julia Kristeva, a partir do conceito de dialogismo, desenvolvido pelo teórico russo Mikhail Bakhtin (2002), aponta para o fato de que um texto se constitui por um conjunto de citaçóes de outros textos, absorvendo-os e transformando-os. Estendendo esse conceito para a produção artístico-comunicativa como um todo, podemos ainda acrescentar que a elaboraçáo de uma obra também traz em si os ecos da época e do contexto social em que foi realizada. São as influências intra e extratextuais que integram o fazer artístico.

O diálogo entre textos e, de forma mais abrangente como é tomado atualmente, entre obras e suportes artísticos, pode ocorrer de diversas maneiras. Um aspecto importante a se destacar é que, ao realizar a intertextualidade, o texto não se relaciona apenas com aquele com quem efetua o diálogo, mas também com os demais do mesmo gênero. No caso da paródia, por exemplo, temos uma relação não só com o texto parodiado, mas com todos os outros parodísticos integrantes daquele gênero. (JENNY et al, 1979).

A intertextualidade propóe uma nova forma de leitura, tanto do novo texto quanto daquele que é trazido para o diálogo. Trata-se de uma intersecção que conecta o texto antigo com a atual situação narrada, estabelecendo uma correlação entre as obras, entre os discursos, numa verdadeira intervenção. A partir daí, podemos ter desde fragmentos da obra-base recuperada na narrativa atual (citaçóes, alusóes, etc.) até novas versóes (paródias, intersecções e outras) que propõem diferentes "olhares" sobre a obra.

$\mathrm{Na}$ relação intertextos, aspectos relacionados à produção e recepção são de vital importância. O conhecimento prévio das obras integrantes do diálogo permitirá uma maior compreensão do interdiscurso proposto. Tal fato, por sua vez, estará sujeito a questôes relacionadas desde a estrutura da obra até a elementos sócio-culturais de cada época. É importante destacar que o processo comunicativo está ligado a aspectos sociais do seu contexto de produção o que, por sua vez, determina a criação e recepção dos produtos culturais das sociedades ao longo de nossa história. 


\section{MúlTIPLOS DIÁLOGOS}

A produção de obras em quadrinhos a partir do material literário revela inúmeras complexidades, o que, por vezes, pode confundir em um primeiro olhar. Tomemos a quadrinização da obra de Kafka, Metamorfose, feita por Peter Kuper, em 2003. De certo que estamos diante de uma adaptação de uma obra literária para a $\mathrm{HQ}$, mas a forma como Kuper utiliza os recursos dos quadrinhos aponta para uma maneira distinta de estabelecer a relação com o texto-base. Todo produzido em preto e branco, o álbum ressoa em seus traços estilizados a ambientação e o estranhamento presentes em Kafka. O verbal ganha a dimensão gráfico-visual e, em determinados momentos, as palavras caminham pelo espaço da página contorcendo-se entre o claro e o escuro das cenas, numa imitação do movimento do inseto que é descrito no texto de Kafka. Vale ressaltar que, nos quadrinhos, a linguagem verbal, bem como a não-verbal, assume um caráter altamente visual. As palavras inserem-se no cenário como as figuras e, se bem explorado, tal recurso amplia as possibilidades comunicativas do meio.

Além desses, outros recursos das HQs auxiliam na elaboração e construção da narrativa, dentre os quais: os balóes, que podem assumir diversos formatos de acordo com o que se deseja expressar, a apresentação dos quadros (regulares, irregulares ou mesmo inexistentes), a cor ou sua ausência, e outras ferramentas gráficas, cuja utilização pode revelar humor, conflito, tensão e muito mais. Explorar os recursos das HQs no processo de adaptação de obras literárias, aliás, é um importante aspecto que o escritor e pesquisador português Pedro Barbosa, baseado na nomenclatura do linguista Roman Jakobson, chama de transposição semiótica: quando ocorre a transposição de obras entre meios artísticos diferentes, temos a variação não apenas do código, mas também da própria natureza dos sinais utilizados (BARBOSA, 2002). Numa adaptação de um texto literário para o cinema, por exemplo, os signos linguísticos são convertidos para imagens audiovisuais; no caso da quadrinização de obras da literatura ocorre a transformação da informação verbal literária em uma narrativa construída por meio de uma sequencialidade de imagens, na qual a 
relação entre as linguagens verbal e não verbal torna-se mais importante do que cada uma considerada separadamente.

Da mesma maneira que a quadrinização feita por Kuper, outras adaptaçôes de textos literários para os quadrinhos fazem uso habilidoso dos recursos das HQs, dando um maior dinamismo à obra final. É o que podemos denominar de uma adaptação criativa, em que a linguagem do novo meio é bem explorada em suas características e nuances próprias. Porém, ainda assim, trata-se de uma adaptação, na medida em que o texto-base é recuperado sem que nenhum elemento novo/diferente interfira no enredo original. Já quando há a presença de outros conteúdos unidos à narrativa, alterando-a de alguma maneira, estamos diante do que podemos denominar de um diálogo intertextual.

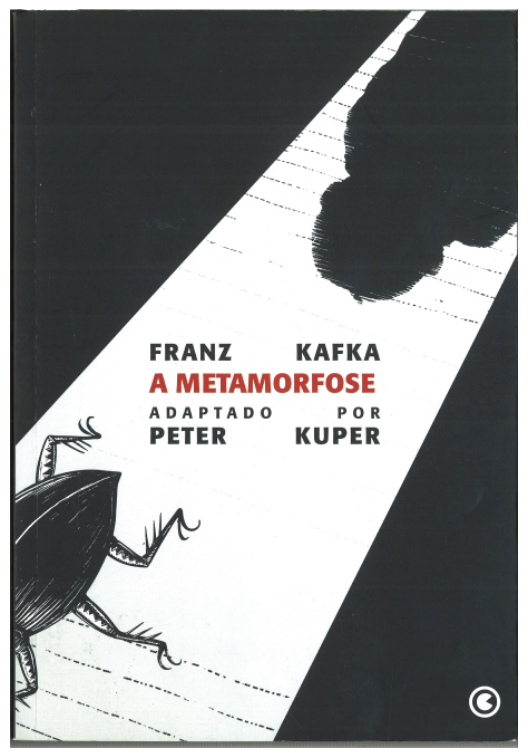

Capa da adaptação de A Metamorfose, de Kafka para os quadrinhos, feita por Peter Kuper - ano: 2004, Editora Conrad. Na HQ o texto do autor tcheco é utilizado na íntegra, sem cortes ou reduçóes. (C) Reprodução

\section{Obras Clássicas da LITERATURA E AS HQS - UM DIÁlogo} RECORRENTE

Um importante "movimento" a ser considerado na relação entre textos literários e quadrinhos é o diálogo que se dá entre os clássicos da literatura e as HQs, sobretudo os contos de fadas e as fábulas. Esses textos integram um acervo de conhecimento popular e 
universal, atravessando épocas e vindo até os nossos dias. Tal fato permite o reconhecimento quase que imediato por parte do leitor/receptor, tornando assim o diálogo entre obras mais efetivo, aspecto este, como apontado anteriormente, altamente relevante quando do estabelecimento de uma relação intertextual entre obras e artes.

Segundo a escritora e crítica literária Nelly Novaes Coelho (1984), a Literatura nasceu do maravilhoso, da dificuldade inicial dos seres humanos, no começo dos tempos, de explicar os fenômenos naturais a que estavam sujeitos. A partir daí surgiram os mitos e as lendas. Os contos de fadas e as fábulas nasceram desse contexto e, no mundo atual, servem de material-base para o diálogo com diferentes obras e suportes, como o cinema, a televisão, os quadrinhos, o teatro, a música e outros. São paródias, novas versóes ou entrecruzamento de histórias diversas, como a série de animação feita para o cinema, Shrek, cuja personagem principal, um ogro, interage com diversas criações de contos clássicos da literatura, como Pinóquio, Gato de Botas, Chapeuzinho Vermelho, A Bela Adormecida, Os Três Porquinhos e muitos outros.

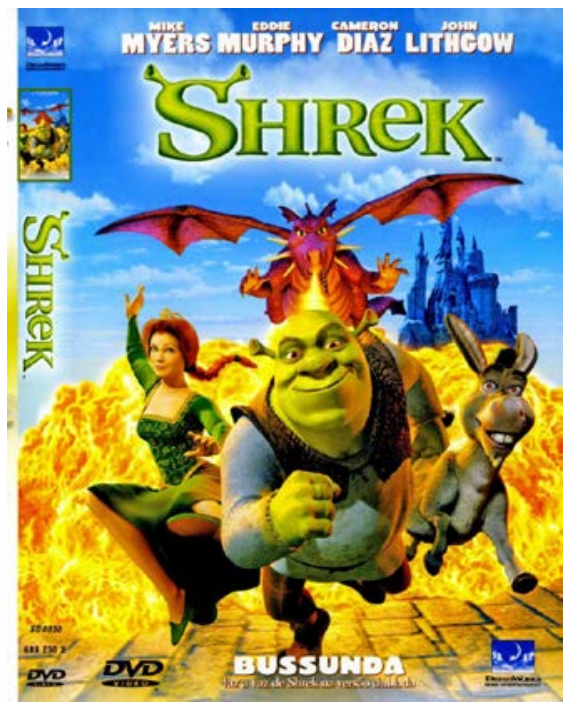

Capa do DVD do filme Shrek, produção de 2007, direção de Chris Miller. A paródia é o elemento principal que rege as relaçôes entre Shrek e as personagens dos contos de fadas e fábulas na animação. ( ) Reprodução

No diálogo intertextual entre os contos clássicos e os quadrinhos uma série de características pode ser observada, como: a absorção do texto original na nova versão proposta, que pode ocorrer por meio do humor, do erotismo, suspense e outras formas; a 
descaracterização de personagens tradicionais que assumem diferentes e renovados papéis na nova narrativa; o uso dos recursos dos quadrinhos para reafirmar e/ou negar situaçóes do texto-base.

Há diversos exemplos desse tipo de inter-relação nas HQs, como é o caso do mangá Cinderalla de Junko Mizuno, produzido em 2006. Com um tom paródico e bastante atual, Junko faz uma releitura da personagem Cinderela, ou melhor, Cinderalla, que, nessa versão, torna-se um zumbi e, após seu encontro com o príncipe, perde o olho ao invés do sapatinho de cristal (uma vez que agora ela é uma morta-viva). Há muitas referências recheadas de humor, que reescrevem o texto e o atualizam. A paródia, aliás, é uma importante forma de intertextualidade. Por meio dela há uma reelaboração da obra-base na qual se propóe uma maneira diferente de interagir com a mesma utilizando uma conscientização crítica. (SANT'ANNA, 1998).

A obra de Junko, cuja leitura se inicia pelo final do livro (da direita para a esquerda), característica própria dos mangás japoneses, apresenta, em traços típicos e cores marcantes, personagens tradicionais contextualizados de uma forma bem diferente. Cinderalla é uma comerciante bastante esforçada e quase sempre retratada com pouca roupa, de forma sensual (assim como outras personagens da narrativa). O príncipe, que se transformou num zumbi após morrer devido a uma doença fatal, é um cantor famoso no mundo dos mortos e só usa pijama, pois, enquanto era vivo, permanecia doente e internado, sendo essa a sua vestimenta mais habitual. A referência à doença e morte do príncipe, importante elemento na construção da nova versão, é feita ora de forma natural, ora trágica, mas prevalecendo o tom irônico, como o fato dele trazer durante quase todo o tempo, bolsas de sangue (ou soro) presas em seu braço, ou ser acompanhado por duas figuras negras (uma espécie de “anjos”) que levam apetrechos médicos (termômetros, injeção, etc.).

Elementos do conto de fadas tradicional estão lá, porém com uma nova leitura. Cinderalla é esforçada e busca seu caminho por meio do trabalho remunerado (ela tem um restaurante e continua a administrá-lo após a morte do pai, que volta como um zumbi para ajudá-la). O príncipe conquista suas fãs pelo fato de ser um cantor famoso; a madrasta e as 
filhas dão muito trabalho, porém não parecem tão más como no conto original. A fada, inicialmente, é mirim e só se transforma em fada adulta, com amplos poderes, depois que consegue ajudar Cinderalla.

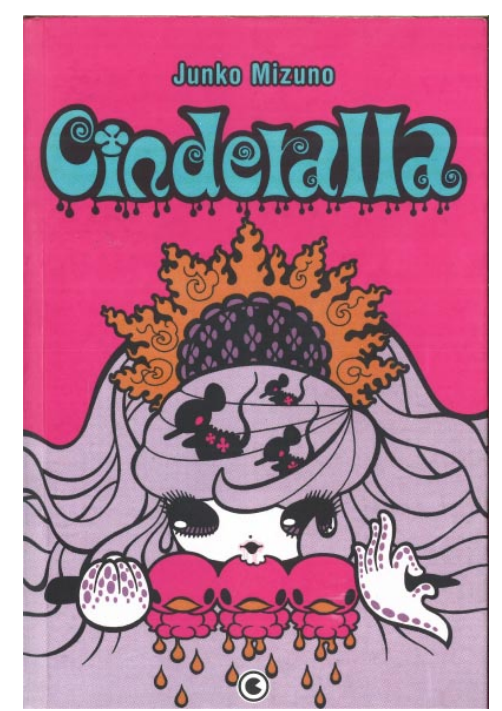

Cinderalla, de Junko Mizuno, ano: 2006, Editora Conrad. A capa do mangá traz Cinderalla saboreando um espetinho de frango (yakitori), com o famoso molho secreto de seu pai, marca registrada do restaurante de ambos. As manchas nas mãos (e em outras partes do corpo) sáo um dos elementos que, no enredo, indica quando a personagem se transformou em zumbi. () Reprodução

\section{ELEMENTOS TRADICIONAIS NA INTER-RELAÇÃO QUADRINHOS E}

\section{LITERATURA}

Outro aspecto importante do diálogo intertextual é a relação que se pode estabelecer entre obras e elementos consagrados produzidos em diferentes meios artísticos. No caso da literatura e dos quadrinhos, tanto um quanto o outro possuem um universo próprio repleto de mitologias, personagens, enredos e outros aspectos que acabam por se tornar cânones, ou seja, são tidos como representativos das suas respectivas áreas, devido à aceitação do público e/ou da crítica em geral.

Vale ressaltar que há muita controvérsia sobre o conceito de cânone, justamente por ser essa uma noção subjetiva e por abarcar em si uma hierarquização em relação aos elementos considerados, entretanto, é possível identificar obras ou determinadas características das mesmas que se consagraram ao longo dos tempos. É o que ocorre, por 
exemplo, com o clássico Romeu e Julieta de Willian Shakespeare, conhecido por muitas pessoas ou entáo Batman, o cavaleiro das trevas, personagem famosa no mundo dos quadrinhos.

Elementos consagrados, seja nos quadrinhos ou na literatura, trazem em si uma força compositiva que encontra eco naqueles que os reconhecem e legitimam suas existências. Ao estabelecermos o diálogo entre tais elementos, colocamos também em intersecção toda a mitologia que os acompanha e que, na relação entre obras, pontuarão a narrativa, emergindo no novo enredo.

A aproximação entre universos ficcionais distintos amplifica um aspecto muito presente nas relações intertextuais: a polifonia. Conceito definido por Bakhtin, o discurso polifônico caracteriza-se pela "multiplicidade de vozes e consciências que mantêm umas com as outras uma relação de igualdade no discurso" (ROMUALDO, 2000, p.54). A inserção do "outro" no discurso, por sua vez, implica numa nova representação da fala/consciência do mesmo, uma vez que ela ganha um caráter renovado ao ser incorporada em outro contexto.

Para que compreendamos melhor como tal relaçáo ocorre na prática, tomemos as obras criadas por Mauricio de Sousa e o diálogo que seus personagens e enredos travam com outros elementos tradicionais da cultura. As personagens e histórias de Mauricio consagraram-se ao longo do tempo, tornando-se conhecidas não só no Brasil, mas também em outras partes do mundo. Expandindo-se para campos de atuação diversos, as personagens tornaram-se garotos-propaganda, porta-vozes de campanhas, produtos de merchandising, além de figurarem diversas histórias nas HQs, várias delas elaboradas por meio de diálogos com textos consagrados da literatura.

Uma delas que podemos destacar para compreender a intertextualidade entre cânones da literatura e dos quadrinhos é a edição no 68 da revista Cascão, de 1989, que traz a história "Cascóquio", cujo nome já aponta para o diálogo travado com o famoso boneco de madeira do livro As aventuras de Pinóquio, escrito pelo italiano Carlo Collodi (pseudônimo de Carlo Lorenzini), em 1881. 
Nessa paródia do clássico Pinóquio, ocorre uma intersecção entre os dois personagens e seus respectivos enredos. A polifonia vem expressa justamente por haver uma absorção, mas não diluição, de aspectos específicos de cada narrativa, que colaboram para a construção do novo enredo. A justificativa para a identificação da criação de Mauricio com a personagem clássica é feita na obra pelo viés do humor. O boneco de madeira criado por "Pepeto" (numa modificação do nome original, Gepeto), assim como seu “irmão" italiano, também vê seu nariz crescer cada vez que mente, mas mantém as raízes no universo de Mauricio de Sousa, uma vez que conserva o pavor da água, fato justificado por ele com a argumentação de que sua madeira pode empenar. Como Pinóquio, a personagem do quadrinho ganha uma consciência externa mas, dessa vez, ao invés de um grilo falante é uma mosca falante, numa referência direta ao Cascáo, que vive rodeado de moscas devido à falta de banho.

O enredo segue a mesma sucessão de aventuras de Pinóquio, porém agora com motivações diferentes, sempre relacionadas a Cascão e suas características próprias (falta de asseio, medo de água, etc.): Cascóquio é um fiasco no teatro de marionetes porque, ao ficar nervoso, espanta o público com seu cheiro de suor; no trem ele é transformado em porco ao invés de burro, como na história original; na hora de salvar seu pai da barriga da baleia, dá um jeito para não se molhar. Ainda há a inserção de outra personagem do universo criado por Mauricio de Sousa, Magali, uma menina gulosa que havia sido transformada em baleia.

Um aspecto importante é o fato de que a base de construção do diálogo proposto em Cascóquio se dá muito mais com a animação Pinóquio, da Disney, realizada em 1940, do que com a história original criada por Collodi, cuja narrativa é mais complexa. A adaptação da Disney, por sua vez, é uma das mais conhecidas e considerada como uma obra-prima do gênero. Temos, portanto, um diálogo do quadrinho com o clássico literário que já vem, por seu lado, "contaminado" por outros diálogos, revelando como a trama intertextual abre espaço para criaçóes das mais variadas e cheias de possibilidades interrelacionais e polifônicas. 


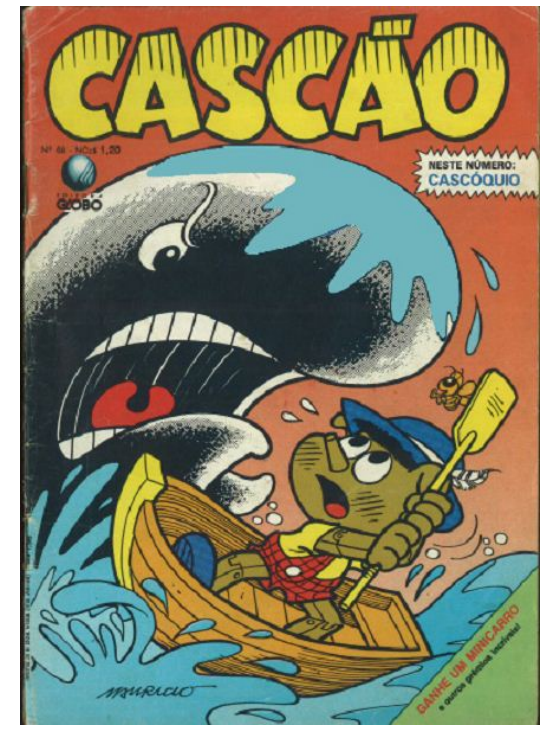

Capa da HQ Cascão, nº 68, ano: 1989, Editora Globo. Cascão encarna nessa obra o boneco de madeira que queria virar menino. CReprodução

\section{NOVAS TESSITURAS NARRATIVAS}

O diálogo intertextual traz à tona diferentes formas de composição revelando possibilidades variadas de intersecção/conexão entre as obras. Seja por meio de um caminho conhecido, resgatando textos tradicionais como os contos de fadas e fábulas e reescrevendoos a partir de novas propostas narrativas, seja pelo confronto de elementos consagrados recontextualizando-os em diferentes situaçôes, as possibilidades do diálogo são muitas.

Nas HQs, a inter-relação com a literatura tem sido cada vez mais explorada. O uso dos recursos dos quadrinhos (a visualidade, o diálogo entre linguagens, a distribuição espacial, etc.) garante, em muitos casos, intersecçôes eficientes entre textos e obras. Mas vale ressaltar que ainda há muito a ser desenvolvido, pois as propostas dialógicas não se esgotam com os modelos já produzidos. Isso sem falar nas inúmeras possibilidades que se abrem para o diálogo na direção contrária, ou seja, o uso do material das HQs pela literatura, que pode render enredos intrigantes e bastante complexos.

Ao levantarmos alguns exemplos da relação dos quadrinhos com a literatura, procuramos destacar como a inserção de novos elementos à narrativas consagradas ou à proposição de outras formas de construção textual para enredos clássicos permite uma reelaboração da forma como interagimos com tais obras. Isso é o que acontece com obras 
como a adaptação de Kupfer para o enredo de Kafka, na qual a linguagem dos quadrinhos e seus recursos narrativos próprios são essenciais para a construção de uma nova forma de leitura da obra original.

É a partir dessa perspectiva, aliás, que conhecemos Cinderalla, uma versão inusitada da singela princesa dos contos de fada, ou então nos reencontramos com Cascão na pele de Cascóquio, um boneco de madeira que nos parece familiar por conta da aproximação com as criaçóes de Mauricio de Sousa. Essas são apenas algumas das maneiras que a inter-relação entre o material literário e os quadrinhos pode assumir. $O$ importante, mais do que aproximar obras e suportes, é que o diálogo permita a construção de um novo "olhar", contribuindo, assim, para diferentes formas de leitura. 


\section{REFERÊNCIAS}

BAKHTIN, Mikhail. A Cultura popular na Idade Média e no Renascimento: $o$ contexto de François Rabelais. São Paulo: Hucitec, 1999.

BAKHTIN, Mikhail. Problemas da poética de Dostoievski. Rio de Janeiro: Forense Universitária, 2002.

BARBOSA, Pedro. Arte, comunicação e semiótica. Porto: Ediçôes Universidade Fernando Pessoa, 2002.

BLOOM, Harold. Shakespeare: a invenção do humano. Tradução José Roberto O’Shea. Rio de Janeiro: Objetiva, 2000.

CAGNIN, Antônio Luis. Os quadrinhos. São Paulo: Ática, 1975.

CARVALHAL, Tânia Franco. Literatura Comparada. São Paulo: Ática, 1986.

CIRNE, Moacy. Para ler os quadrinhos: da narrativa cinematográfica à narrativa quadrinizada. Petrópolis: Vozes, 1972.

COELHO, Nelly Novaes. Panorama histórico da literatura infantil e juvenil. $3^{\mathrm{a}} \mathrm{ed}$. rev. São Paulo: Quíron, 1984.

COELHO, Nelly Novaes. O conto de fadas. São Paulo: Editora Ática, 1987.

COLlODI, Carlo. As aventuras de Pinóquio: história de uma marionete. Tradução Maria Colasanti; il. Odilon Moraes. São Paulo: Companhia das Letrinhas, 2002.

DISCINI, Norma. Intertextualidade e conto maravilhoso. São Paulo: Humanitas, 2002.

EISNER, Will. Narrativas Gráficas. São Paulo: Devir, 2005.

JAKOBSON, Roman. Linguística e Comunicação. São Paulo: Cultrix, 2001.

JENNY, Laurent et al. Intertextualidades. Tradução Clara Crabbé Rocha. Coimbra: Livraria Almedina, 1979.

KUPER, Peter. A Metamorfose. São Paulo: Conrad, 2004.

LOTMAN, Iuri. A estrutura do texto artístico. Tradução Maria do Carmo Vieira Raposo e Alberto Raposo. Lisboa: Editorial Estampa, 1978. 
LUYTEN, Sônia Bibe (org.). Mangá - O poder dos quadrinhos japoneses. São Paulo: Liberdade, 1991.

McCLOUD, Scott. Desvendando os quadrinhos. São Paulo: M. Books, 2002.

MIZUNO, Junko. Cinderalla. Tradução Drik Sada. São Paulo: Conrad, 2006.

MOISÉS, Leyla Perrone. Literatura Comparada, intertexto e antropofagia. In Flores da Escrivaninha. São Paulo: Companhia das Letras, 1990.

NITRINI, Sandra. Literatura comparada: história, teoria e crítica. São Paulo: EDUSP, 2000 .

OLIVEIRA, M.C.X. A Arte dos Quadrinhos e o Literário A contribuição do diálogo entre o Verbal e o Visual para a reprodução e inovação dos modelos clássicos da cultura. 2008. Tese (Doutorado em Estudos Comparados de Literaturas de Língua Portuguesa). São Paulo: Universidade de São Paulo - USP, 2008.

ROMUALDO, Edson Carlos. Charge Jornalistica: intertextualidade e polifonia. Maringá: Universidade Estadual de Maringá, 2000

SANT'ANNA, Affonso Romano. Paródia, paráfrase \& Cia. 7. ed. São Paulo: Ática, 2002.

SOUSA, Mauricio. Cascóquio. In Cascão nº68. São Paulo: Editora Globo, 1989.

TODOROV, T. Os gêneros do discurso. Tradução Elisa Angotti Kossovitch. São Paulo: Martins Fontes, 1980. 